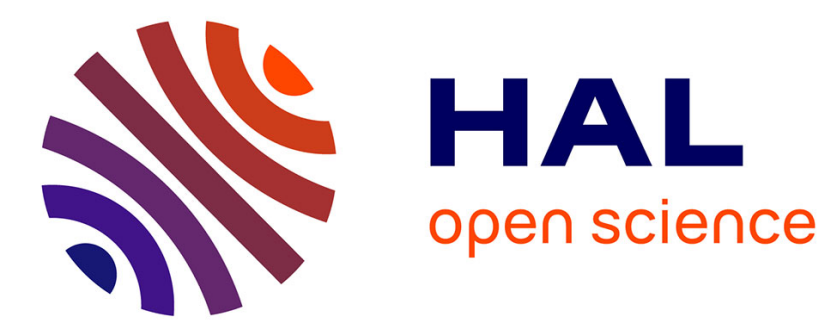

\title{
Improvements on the optical properties of Ge-Sb-Se chalcogenide glasses with iodine incorporation
}

Chen Jiang, Xunsi Wang, Qingde Zhu, Qiuhua Nie, Minming Zhu, Peiquan Zhang, Shixun Dai, Xiang Shen, Tiefeng Xu, Ci Cheng, et al.

\section{- To cite this version:}

Chen Jiang, Xunsi Wang, Qingde Zhu, Qiuhua Nie, Minming Zhu, et al.. Improvements on the optical properties of Ge-Sb-Se chalcogenide glasses with iodine incorporation. Infrared Physics and Technology, 2015, 73, pp.54-61. 10.1016/j.infrared.2015.09.001 • hal-01198729

HAL Id: hal-01198729

https://hal-univ-rennes1.archives-ouvertes.fr/hal-01198729

Submitted on 17 Sep 2015

HAL is a multi-disciplinary open access archive for the deposit and dissemination of scientific research documents, whether they are published or not. The documents may come from teaching and research institutions in France or abroad, or from public or private research centers.
L'archive ouverte pluridisciplinaire $\mathbf{H A L}$, est destinée au dépôt et à la diffusion de documents scientifiques de niveau recherche, publiés ou non, émanant des établissements d'enseignement et de recherche français ou étrangers, des laboratoires publics ou privés. 


\title{
Improvements on the optical properties of Ge-Sb-Se chalcogenide glasses with iodine incorporation
}

\author{
Chen Jiang ${ }^{1}$, Xunsi Wang ${ }^{1 *}$, Qingde Zhu ${ }^{1}$, Qiuhua Nie ${ }^{1}$, Minming Zhu ${ }^{1}$, Peiquan Zhang ${ }^{1}$, Shixun \\ Dai $^{1}$, Xiang Shen ${ }^{1}$, Tiefeng $\mathrm{Xu}^{1}$, Ci Cheng ${ }^{1}$, Fangxing Liao ${ }^{1}, Z_{i j u n ~ L i u}{ }^{1}$, and Xianghua Zhang ${ }^{2}$ \\ ${ }^{1}$ Laboratory of Infrared Material and Devices, Advanced Technology Research Institute, Ningbo, Zhejiang, 315211, China \\ ${ }^{2}$ Laboratory of Glasses and Ceramics, UMR 6226 CNRS-University of Rennes 1, Rennes Cedex, 135042, France \\ *xunsiwang@siom.ac.cn Tel.:+86-574-87600947
}

\begin{abstract}
Decreasing glass network defects and improving optical transmittance are essential work for material researchers. We studied the function of halogen iodine (I) acting as a glass network modifier in $\mathrm{Ge}-\mathrm{Sb}-\mathrm{Se}-$ based chalcogenide glass system. A systematic series of $\mathrm{Ge}_{20} \mathrm{Sb}_{5} \mathrm{Se}_{75-\mathrm{x}} \mathrm{I}_{\mathrm{x}}(\mathrm{x}=0,5,10,15,20$ at\%) infrared (IR) chalcohalide glasses were investigated to decrease the weak absorption tail (WAT) and improve the mid-IR transparency. The mechanisms of the halogen I affecting the physical, thermal, and optical properties of Se-based chalcogenide glasses were reported. The structural evolutions of these glasses were also revealed by Raman spectroscopy and camera imaging. The progressive substitution of I for Se increased the optical bandgap. The WAT and scatting loss significantly decreased corresponding to the progressive decrease in structural defects caused by dangling bands and structure defects in the original $\mathrm{Ge}_{20} \mathrm{Sb}_{5} \mathrm{Se}_{75}$ glass. The achieved maximum IR transparency of $\mathrm{Ge}-\mathrm{Sb}-\mathrm{Se}-\mathrm{I}$ glasses can reach up to $80 \%$ with an effective transmission window between $0.94 \mu \mathrm{m}$ to $17 \mu \mathrm{m}$, whereas the absorption coefficient decreased to $0.029 \mathrm{~cm}^{-1}$ at $10.16 \mu \mathrm{m}$. Thus, these materials are promising candidates for developing low-loss IR fibers.
\end{abstract}

Keywords: Glass and other amorphous materials; Fiber materials; Optical properties; infrared spectroscopy; Raman spectroscopy.

\section{Introduction}

The development of infrared (IR) technologies such as night vision cameras and bio-optical sensors in recent decades has raised interest on the investigation of materials used for IR fibers with low attenuation [1]. Ideal candidate materials should have several specified features, such as an exceedingly wide transparency window, good thermal properties for fiber drawing, and good chemical stability [2]. Chalcogenide glasses have been proposed as promising candidates for use in IR fibers because of their wide transparent window that covers the atmospheric IR windows of $3 \mu \mathrm{m}$ to $5 \mu \mathrm{m}$ and $8 \mu \mathrm{m}$ to $12 \mu \mathrm{m}$, strong glass forming tendency, good stability against crystallization, and good chemical durability to resist corrosion compared with other non-oxide glasses [3, 4].

Among these glasses, the conventional selenium based Ge-Sb-Se glasses have large glass-forming regions and excellent thermal stability to be molded into lenses or drawn into fibers. However, the short-wavelength weak absorption tail (WAT) of these glasses is excessively high that seriously enhances attenuation loss in the fibers. Given that the WAT normally comes from structural defects in the glass network [5], it is hard to remove once the composition or glass structure has been decided. Sanghera et al. proposed that the theoretical attenuation loss of selenide-based glasses may not be achieved because of the glass network defects, thus the existence of the WAT [6]. The transparency of these glasses in the mid-IR region is usually approximately $50 \%$, which is far below the ideal value and should be further improved [7]. The shortcomings mentioned above have limited their further applications in the area of novel IR, low-loss chalcogenide fibers. 
However, if the glass network was improved and the defects in the glass network were decreased to a certain extent in a specific way, the absorption coefficient in the WAT can be lowered to a new level. Zhang et al. previously reported that halogen-doped chalcogenide glasses had low optical transmittance loss in atmospheric IR windows [8]. Thus, this trial provides a reference to comprehensively study the influence of the halide iodine (I) on the structure and properties of Se-based chalcogenide glasses.

We attempt to investigate the effects of the $\mathrm{Ge}_{20} \mathrm{Sb}_{5} \mathrm{Se}_{75-\mathrm{x}} \mathrm{I}_{\mathrm{x}}(\mathrm{x}=0,5,10,15,20$ at $\%)$ glass system on the glass structure of selenium-based glasses and compositional dependence of its optical properties to improve the transparency of the Ge-Sb-Se glass system using the halogen element I to replace Se. Raman spectroscopy, X-ray diffraction (XRD), and other optical spectra methods have been employed to evaluate the impact of the replacement on the structural modification. The optical effects of halide I on the Ge-Sb-Se-I glasses were discussed systematically using ultraviolet-visible-near-IR (UV-vis-NIR) absorption, and Fourier transform IR (FTIR) optical spectra. The optical parameters (i.e., molar refraction, metallization criterion, and optical band gap) were also calculated.

\section{Experiments}

A series of $\mathrm{Ge}_{20} \mathrm{Sb}_{5} \mathrm{Se}_{75-\mathrm{x}} \mathrm{I}_{\mathrm{x}}(\mathrm{x}=0,5,10,15,20$ at $\%)$ glass samples were prepared by the traditional melt-quenching method and marked from G0 to G4. Elemental raw materials of high purity (i.e., Ge, 99.999\%, Sb, 99.999\%, Se, 99.999\%, and I, 99.99\%) with no further purification were carefully weighed and batched into quart ampoules, which were sealed under vacuum at a pressure of $2 \times 10^{-4} \mathrm{~Pa}$ using a gas-oxygen torch. The quartz ampoules containing the raw materials were then heated slowly to $850{ }^{\circ} \mathrm{C}$ in rocking furnaces and maintained at this temperature for $20 \mathrm{~h}$ to ensure homogenization of the mixtures. Once homogenized, the melt-containing ampoules were quenched in water at room temperature and swiftly moved to a preheated furnace to anneal for $8 \mathrm{~h}$ to minimize the inner tension induced by the quenching step. The glass rods $(8 \mathrm{~mm}$ in diameter and $50 \mathrm{~mm}$ in length) were then obtained by removing them from the ampoules and finally cutting them into discs of thicknesses $d$ as listed in Table1. They were then polished to mirror smoothness on both sides for optical testing.

Table 1. Glass sample properties.

\begin{tabular}{cccccc}
\hline sample & composition & $\rho\left(\mathrm{g} \mathrm{cm}^{-3}\right)$ & $\mathrm{d}(\mathrm{cm})$ & $\mathrm{T}_{\mathrm{g}}\left({ }^{\circ} \mathrm{C}\right)$ & $\mathrm{T}_{\mathrm{p}}\left({ }^{\circ} \mathrm{C}\right)$ \\
\hline $\mathrm{G} 0$ & $\mathrm{Ge}_{20} \mathrm{Sb}_{5} \mathrm{Se}_{75}$ & 4.591 & 0.21 & 185.01 & 219.13 \\
$\mathrm{G} 1$ & $\mathrm{Ge}_{20} \mathrm{Sb}_{5} \mathrm{Se}_{70} \mathrm{I}_{5}$ & 4.396 & 0.20 & 171.03 & 201.19 \\
$\mathrm{G} 2$ & $\mathrm{Ge}_{20} \mathrm{Sb}_{5} \mathrm{Se}_{65} \mathrm{I}_{10}$ & 4.385 & 0.19 & 163.81 & 199.65 \\
$\mathrm{G} 3$ & $\mathrm{Ge}_{20} \mathrm{Sb}_{5} \mathrm{Se}_{60} \mathrm{I}_{15}$ & 4.376 & 0.21 & 147.25 & 189.15 \\
$\mathrm{G} 4$ & $\mathrm{Ge}_{20} \mathrm{Sb}_{5} \mathrm{Se}_{55} \mathrm{I}_{20}$ & 4.368 & 0.20 & 131.48 & 174.18 \\
\hline
\end{tabular}

Densities were measured according to the Archimedes principle using distilled water as immersion fluid with an accuracy of $0.001 \mathrm{~g} / \mathrm{cm}^{3}$. The amorphous nature of the glasses was determined by the powder XRD method with a powder diffractometer (BRUKER AXS GMBH) using $\mathrm{CuK}_{\alpha}$ radiation (36 $\mathrm{kV}, 20 \mathrm{~mA}$ ). The thermal parameters (i.e., $T_{g}$ and $T_{p}$ ) of these glasses were investigated with a thermal dilatometer (Netzsch DIL402) for the sample thickness of approximately $2 \mathrm{~mm}$. The refractive indexes of samples were obtained using a Prism Coupling Device (SAIRON SPA4000, South Korea). Raman spectra of these glasses were measured at room temperature using the back $\left(180^{\circ}\right)$ scattering configuration of a laser confocal Raman spectrometer (type: Renishaw inVia, Gloucestershire, UK) 
with an Ar ion laser of $488 \mathrm{~nm}$ wavelength. A grating with 1800 grooves $/ \mathrm{mm}$ was used in these measurements. The Vis-NIR absorption spectra of the glass samples were recorded in the range of 400 $\mathrm{nm}$ to $2500 \mathrm{~nm}$ using a Perkin-Elmer Lambda 950 UV-vis-NIR spectrophotometer. The IR transmission spectra of the glass samples were obtained in the range of $4000 \mathrm{~cm}^{-1}$ to $400 \mathrm{~cm}^{-1}$ using a Nicolet380 FTIR spectrophotometer. All the optical tests were conducted at room temperature.

\section{Results and discussion}

\subsection{XRD investigations}

Given that these glasses are black and totally opaque in the visible region (Fig. 1a), visual examination is impossible. However, examination with an NIR imaging camera operating at the wavelength of $1 \mu \mathrm{m}$ indicates no evidence of crystal formation. Results show that fewer and smaller glass stripes appear in the glass and the transparency is gradually improved with the increasing I content (Fig. 1b). XRD analyses were conducted to further determine the amorphous state of each sample. The XRD patterns of the G0 to G4 glass samples are presented in Fig. 2. No sharp peaks and crystalline phases are observed in the measured XRD spectra, so the amorphous nature of the synthesized glasses can be confirmed [9].
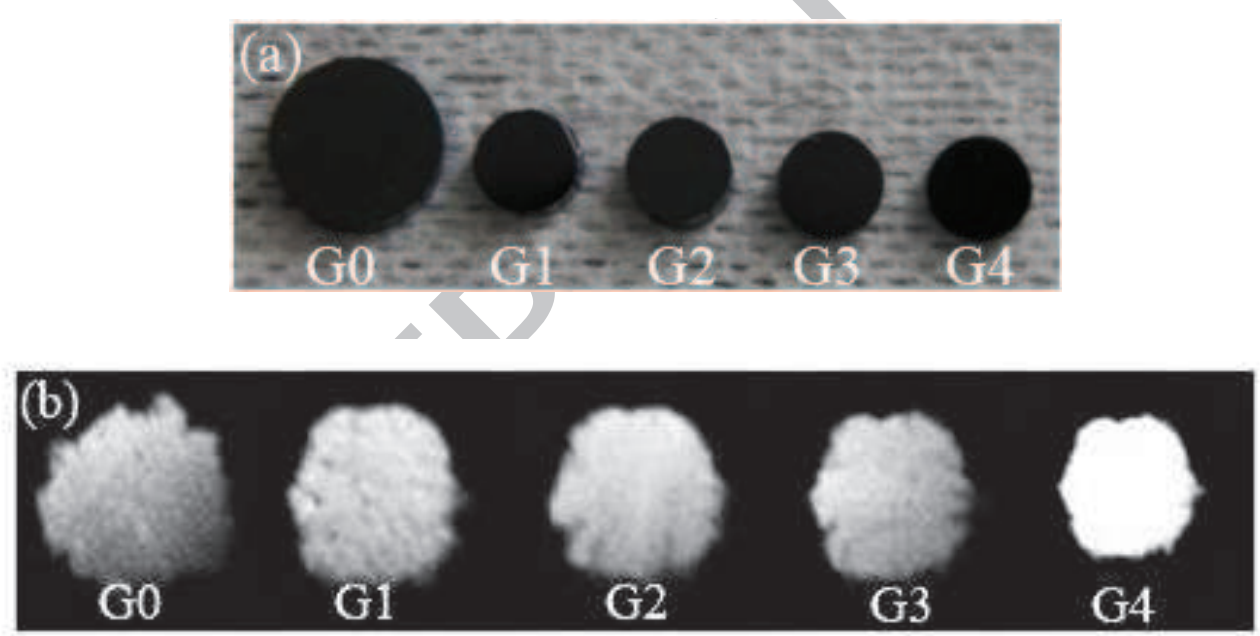

Fig. 1. (a) Visible region images. (b) Images of strips in different glasses taken with an NIR imaging camera operating at a wavelength of $1 \mu \mathrm{m}$.

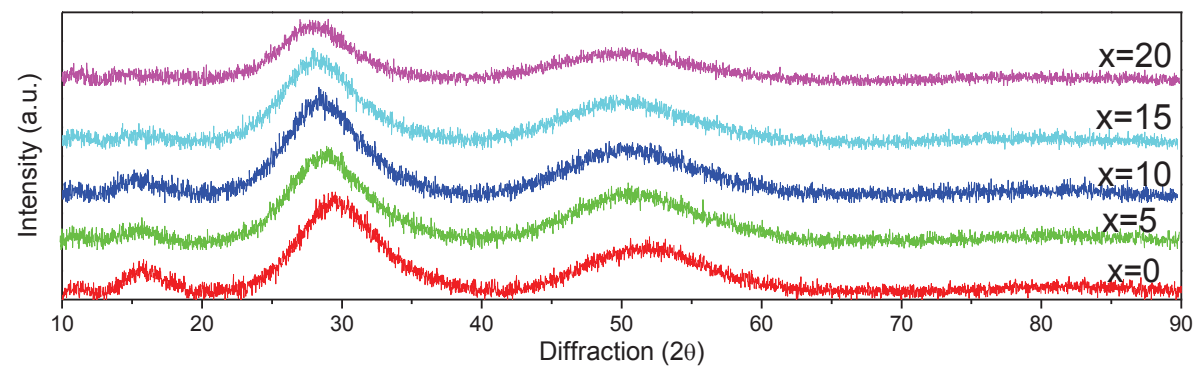

Fig. 2. XRD pattern of the $\mathrm{Ge}_{20} \mathrm{Sb}_{5} \mathrm{Se}_{75-\mathrm{x}} \mathrm{I}_{\mathrm{x}}$ glass samples.

\subsection{Physical and thermal properties}

The densities of the glass samples are shown in Fig. 3, and the density measurements results for these analyzed samples are listed in Table 1. The density decreases rapidly from G0 to G4, which is 
determined by the mean atom molar mass and packing efficiency of atoms $[10,11]$. As the I content increases, the packing efficiency of atoms in the glass structure decreases and increases the average molar volume $\left(V_{m}\right)$ as displayed in Table 3. Despite the larger atomic weight of I (127) than that of Se (79), the measured density $\rho$ decreases with the addition of I.

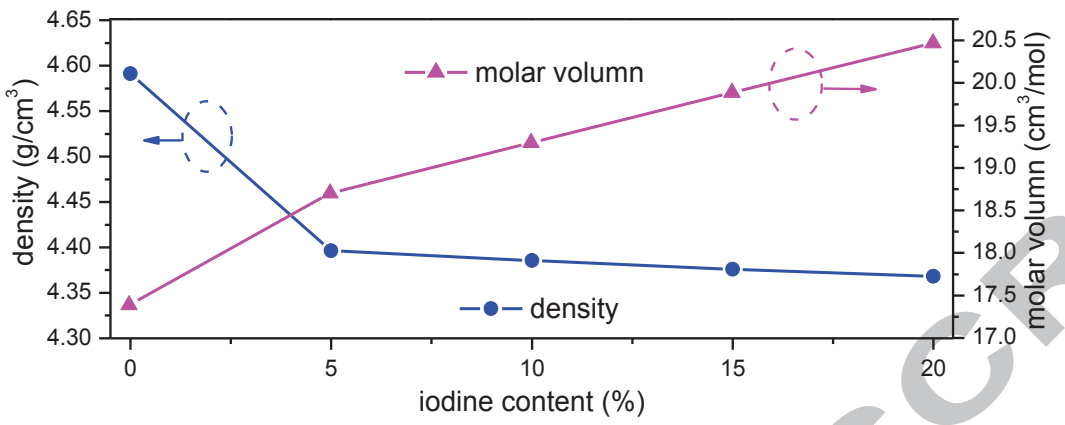

Fig. 3. Densities and molar volume of the $\mathrm{Ge}_{20} \mathrm{Sb}_{5} \mathrm{Se}_{75-\mathrm{x}} \mathrm{I}_{\mathrm{x}}$ glass samples.

The thermal characteristics of the glass samples were investigated using the thermal dilatometer. Table 1 and Fig. 4 shows that the $T_{g}$ value decreases with the increasing I content. A minimum $T_{g}$ value of $131.48{ }^{\circ} \mathrm{C}$ was obtained with a glass composition of $\mathrm{Ge}_{20} \mathrm{Sb}_{5} \mathrm{Se}_{55} \mathrm{I}_{20}$.

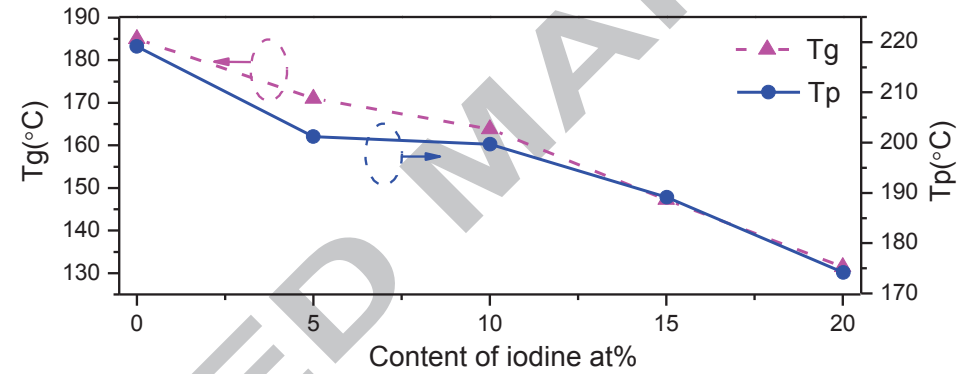

Fig. 4. Thermal parameters of the $\mathrm{Ge}_{20} \mathrm{Sb}_{5} \mathrm{Se}_{75-\mathrm{x}} \mathrm{I}_{\mathrm{x}}$ glass samples.

The decrease in the glass transition temperature $T_{g}$ can be sourced from the difference in the average bond energy of the glasses. The energies of different possible bonds listed in Table 2 can be calculated on the basis of the relation postulated by Pauling [12].

$$
D(a-b)=[D(a-a) * D(b-b)]^{0.5}+30\left(\chi_{a}-\chi_{b}\right)^{2}
$$

where $\chi_{a}$ and $\chi_{b}$ are the electronegativity values of atoms a and $\mathrm{b}$, and $\mathrm{D}(\mathrm{a}-\mathrm{a})$ and $\mathrm{D}(\mathrm{b}-\mathrm{b})$ are the bond energies of the $\mathrm{a}-\mathrm{a}$ and $\mathrm{b}-\mathrm{b}$ bonds, respectively.

The bonds are formed in the sequence of decreasing bond energies until all available valances for the atoms are saturated $[13,14]$. The drop in the $T_{g}$ and $T_{p}$ in this Ge-Sb-Se-I glass system is due to the formation of the weaker Ge-I and Se-I bonds, as well as the reduction in the stronger $\mathrm{Ge}-\mathrm{Se}, \mathrm{Se}-\mathrm{Se}$, and $\mathrm{Sb}-\mathrm{Se}$ bonds (which is confirmed by a succeeding Raman investigation) with the addition of I to $\mathrm{Ge}-\mathrm{Sb}-\mathrm{Se}$ glasses. The smaller the average bond energy is, the lower the glass transition temperature of an amorphous glass system becomes.

Table 2. Bond energy values of different possible bonds.

\begin{tabular}{ll}
\hline bonds & Bond energy $(\mathrm{KJ} / \mathrm{mol})$ \\
\hline
\end{tabular}




\begin{tabular}{cc}
\hline Ge-Se & 205.607 \\
Ge-I & 186.971 \\
Se-Se & 184.096 \\
Sb-Se & 183.845 \\
Se-I & 167.929 \\
Ge-Ge & 154.808 \\
I-I & 151.001 \\
Sb-I & 145.675 \\
Ge-Sb & 141.168 \\
Sb-Sb & 126.440 \\
\hline
\end{tabular}

The $T_{p}$ values (the thermal expansion coefficient reaches the peak value at this temperature) of these glasses are near $200{ }^{\circ} \mathrm{C}$, which are close to the heat deflection temperature of polyethersulfone (PES) $203{ }^{\circ} \mathrm{C}$ and make the fiber coating with polymer PES possible.

\subsection{Energy gap and metallization criterion analysis}

A photon with a certain range of energy can be absorbed by intermediate ions in both crystalline and amorphous materials through three types of absorption mechanisms in solids: (i) free carrier absorption, (ii) lattice absorption, and (iii) electronic interband absorption. The absorption edge occurs at $h v=E_{g}$, which is the energy gap. Duffy [15] suggested that a good correlation exists between the energy gap $\left(E_{g}\right)$ of chalcogenide glasses and their metallization criterion $M[16]$ as follows:

$$
\begin{gathered}
E_{g}=20 M^{2} \\
M=1-\left(R_{m} / V_{m}\right)
\end{gathered}
$$

where $R_{m}$ is the molar refraction and $V_{m}$ is the molar volume. The molar volume of a given composition is calculated using the following formula [17]:

$$
V_{m}=\frac{\sum_{i} Q_{i}}{\rho}
$$

where $Q_{i}$ denotes the molar mass of the glass, $\mathrm{Q}_{\mathrm{i}}=\mathrm{C}_{\mathrm{i}} \mathrm{D}_{\mathrm{i}}$ (i.e., $C_{i}$ is the molar concentration, and $D_{i}$ is the molecular weight of the component). The molar refraction of chalcogenide glasses can be calculated on the basis of their refractive index $(n)$ and molar volume $\left(V_{m}\right)$ by the Lorenz equation as follows:

$$
R_{m}=\frac{\left(n^{2}-1\right)}{\left(n^{2}+2\right)} \times V_{m}
$$

The refractive index of the glass system, which decreases with increasing I content in the glass samples, has been obtained with the help of the prism-coupling technique. The decrease in refractive 
index with the increasing I content is due to the decreased polarizability.

All the optical parameters above are listed in Table 3. The increased content of incorporated I is mainly responsible for the increase in $E_{g}$ for the studied glass samples. The refractive index decreases with the increase in I content, whereas the molar volume, energy gap, and metallization criterion increases. The highest value of the metallization criterion (0.411) corresponds to the G4 glass with the highest energy band gap. A larger metallization criterion value means that the widths of both valence and conduction bands decreases, which results in a wider band gap.

Table 3. Derived characteristic parameters of the studied glasses.

\begin{tabular}{cccccccc}
\hline sample & $\mathrm{n}$ & $\begin{array}{c}\mathrm{V}_{\mathrm{m}}\left(\mathrm{cm}^{3}\right. \\
\left.\mathrm{mol}^{-1}\right)\end{array}$ & $\begin{array}{c}\mathrm{R}_{\mathrm{m}}\left(\mathrm{cm}^{3}\right. \\
\left.\mathrm{mol}^{-1}\right)\end{array}$ & $\mathrm{E}_{\mathrm{g}}(\mathrm{eV})$ & $\mathrm{M}$ & $\begin{array}{c}\mathrm{E}_{\text {opt-dir }} \\
(\mathrm{eV})\end{array}$ & $\begin{array}{c}\mathrm{E}_{\text {opt-indir }} \\
(\mathrm{eV})\end{array}$ \\
\hline $\mathrm{G} 0$ & 2.626 & 17.387 & 11.523 & 2.274 & 0.337 & 1.329 & 1.253 \\
$\mathrm{G} 1$ & 2.529 & 18.703 & 12.021 & 2.553 & 0.357 & 1.403 & 1.314 \\
$\mathrm{G} 2$ & 2.433 & 19.295 & 11.985 & 2.869 & 0.378 & 1.457 & 1.368 \\
$\mathrm{G} 3$ & 2.349 & 19.886 & 11.951 & 3.184 & 0.399 & 1.518 & 1.444 \\
$\mathrm{G} 4$ & 2.301 & 20.470 & 12.051 & 3.382 & 0.411 & 1.598 & 1.526 \\
\hline
\end{tabular}

\subsection{Analysis of Vis-NIR absorption edges and optical band gap}

The absorption coefficient is provided by the following quadratic equation, which is often called the Tauc law [18]:

$$
\alpha(\omega) \hbar \omega=B\left(\hbar \omega-E_{o p t}\right)^{m}
$$

where $E_{\text {opt }}$ is the Tauc optical band gap, $\alpha=2.303 A / d$ (i.e., $A$ is the optical density, and $d$ is the sample thickness), $\omega$ is the incident light angular frequency, and $m$ is a parameter that depends on the transition type of the absorption edge. $m$ is equal to $1 / 2,2,3 / 2$, and 3 for direct allowed, indirect allowed, direct forbidden, and indirect forbidden transitions, respectively. $B$ is a constant that depends on the width of the localized states in the band gap and expressed as follows:

$$
B=\left((4 \pi / c) \sigma_{0}\right) /\left(n_{0} \Delta E\right)
$$

where $n_{0}$ is the static refractive index, $\Delta E$ the located-state tail width, $c$ the light velocity in vacuum, and $\sigma_{0}$ the minimum metallic conductivity. 


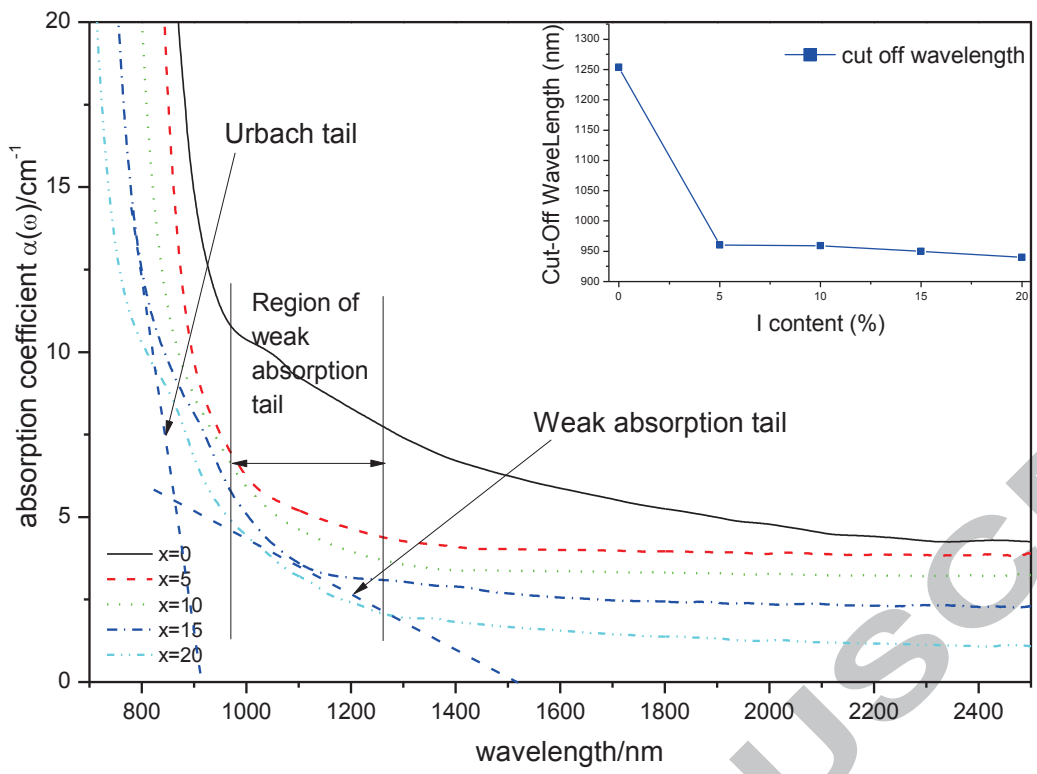

Fig. 5. Absorption spectra of the $\mathrm{Ge}_{20} \mathrm{Sb}_{5} \mathrm{Se}_{75-\mathrm{x}} \mathrm{I}_{\mathrm{x}}$ glass samples. The upper right inset figure shows the cut-off wavelength (half of the maxi transmission) varying with the I content.

The measured Vis-NIR absorption spectra of the glass samples are shown in Fig. 5. In the short-wavelength region, each loss consists of two exponential parts. The steep sloping line corresponds to the Urbach tail and the gradual sloping line to the WAT. The WAT dominates the loss factors in chalcogenide glass fibers [19]. Before the addition of I, the absorption coefficient of $\mathrm{Ge}_{20} \mathrm{Sb}_{5} \mathrm{Se}_{75}$ glass is excessively high in the WAT region (Fig. 5). However, the WAT amplitude of the $\mathrm{Ge}_{20} \mathrm{Sb}_{5} \mathrm{Se}_{75-\mathrm{x}} \mathrm{I}_{\mathrm{x}}$ glass has considerably decreased with the gradual substitution of I for Se from $\mathrm{x}=5$ to $\mathrm{x}=20$.

These results fit well with the WAT model presented by Wood and Tauc. A WAT is induced by additional band-gap states. The tail magnitude is determined by the total concentration of the states. The tail absorption is due to weak transitions between localized states deep in the gap and the extended states of conduction band (or valence band), which can be expressed as the following Equation [5]:

$$
\alpha(\omega)=\frac{\pi^{2} e^{2} \hbar}{m c} \frac{f}{n} \int_{\left(\hbar \omega_{\max }-\hbar \omega\right)}^{\infty} V\left(E_{i}\right) N\left(E_{i}\right) \times g\left(\hbar \omega-\hbar \omega_{\max }+E_{i}\right) d E_{i}
$$

where $e, m, c$, and $n$ represent the electronic charge, mass of electron, velocity of light, and refractive index, respectively; $f$ is the oscillator strength; $\hbar \omega_{\max }$ is the maximum optical transition energy in the tail absorption; $V(E)$ is the volume of the localized states in glass; $N(E)$ is the density of the localized states; and $g(E)$ represents the state density of the opposite extended states in the transition process. The structural disorder, defects, or impurities were attributed to the origin of localized states.

Thus, high $N(E)$ or the transition probability of the localized states in the $\mathrm{Ge}_{20} \mathrm{Sb}_{5} \mathrm{Se}_{75}$ glass appeared to induce the increased tail absorption compared with the Ge-Sb-Se-I glasses. An inherent structural difference between the two glasses can be responsible for this behavior. A certain amount of dangling bonds is present in the glass network of the $\mathrm{Ge}_{20} \mathrm{Sb}_{5} \mathrm{Se}_{75}$ glass, which is regarded as a typical source of glass defects and absorption loss for $\mathrm{Ge}_{20} \mathrm{Sb}_{5} \mathrm{Se}_{75}$ glass $[5,20]$. These structural imperfections can be found in the chainlike structure of $\mathrm{Se}-\mathrm{Se}$ or some $\mathrm{Ge}(\mathrm{Sb})-\mathrm{Se}$ units. Thus, the Ge-Sb-Se glass possibly has a high density of localized states [21]. 
Another special character of the absorption spectra is that the optical absorption edge shifts to a short-wavelength region gradually because of the presence of I in the pseudo-ternary Ge-Sb-Se glass system. The absorption cut-off edge was located between $940 \mathrm{~nm}$ and $1000 \mathrm{~nm}$ with the increasing I content. This scenario is most likely due to the addition of I with higher electronegativity and the glass network broadens the width of the forbidden band, which results in the blue-shift of the short-wavelength, cut-off absorption edge [22].

The plots of $(\alpha(\omega) \hbar \omega)^{1 / 2}$ and $(\alpha(\omega) \hbar \omega)^{2}$ as a function of $\hbar \omega$ in $\mathrm{eV}$ for the five glass samples are shown in Figs. 6 and 7. The values of the direct optical band gap and indirect optical band gap of the $\mathrm{Ge}_{20} \mathrm{Sb}_{5} \mathrm{Se}_{75-\mathrm{x}} \mathrm{I}_{\mathrm{x}}$ glass system were determined to be in the ranges of $1.329 \mathrm{eV}$ to $1.598 \mathrm{eV}$ and 1.253 $\mathrm{eV}$ to $1.526 \mathrm{eV}$ by extrapolating the linear portion of the curves to zero absorption (Table 3 ).

As the absorption coefficient in the UV and visible wavelength bands is mostly caused by the electronic transition over the band gap energy in chalcogenide glasses, the optical absorption edge energy can be used for a relative comparison of losses between two glasses. The tendency of the compositional dependence of $E_{\text {opt }}$ values is that the optical band gap increases with the increase in I content and decrease in Se content. The largest obtained $E_{\text {opt }}$ value implies that the $\mathrm{I}_{20}$ glass can show lower attenuation loss than that of other studied glasses in the energy region where the electronic transition dominates.

The optical bandgap is influenced not only by the chemical composition but also by the structural arrangement of the sample matrix. With the increase in I content, the changes in bond angles and/or bond lengths can modify the glassy structure and disturb the lattice ordering. The result that the compositions with higher I content show higher values of the optical band gap can be related to the tendency of I atoms to cause chemical disordering. Thus, the structural arrangement of the studied glasses is in harmony with a higher optical band gap.

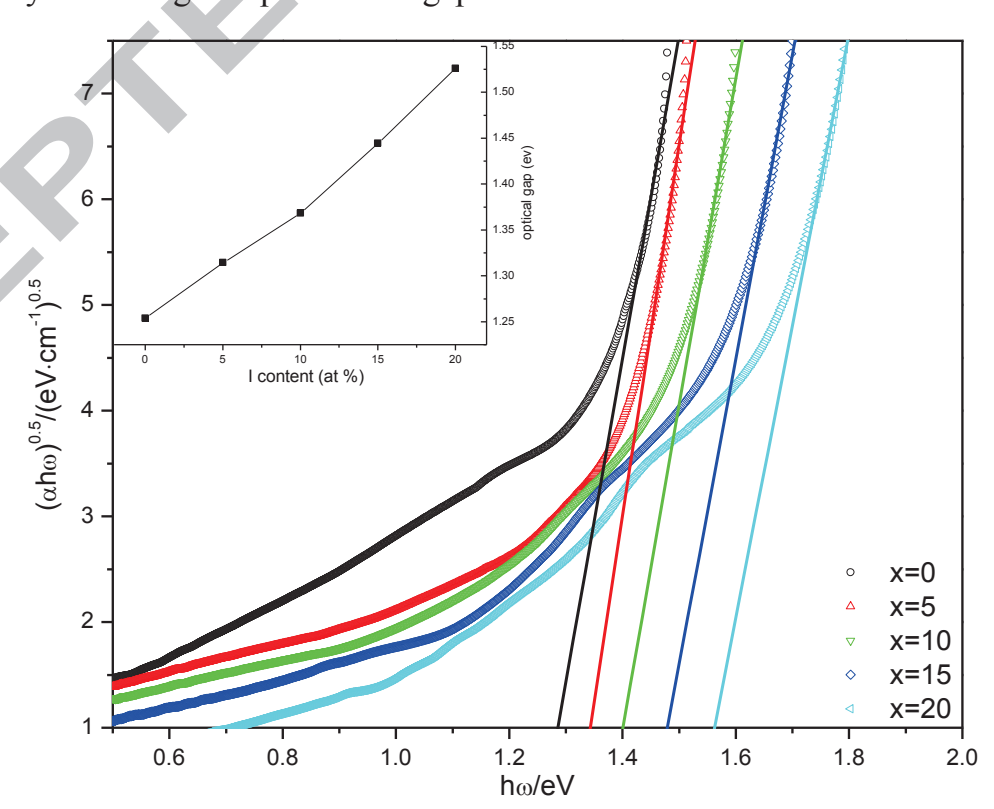

Fig. 6. Relationship between $(\alpha(\omega) \hbar \omega)^{1 / 2}$ and $\hbar \omega$ for glass samples. The upper left inset figure shows the relationship between the optical gap $E_{\text {opt }}$ and I contents. 


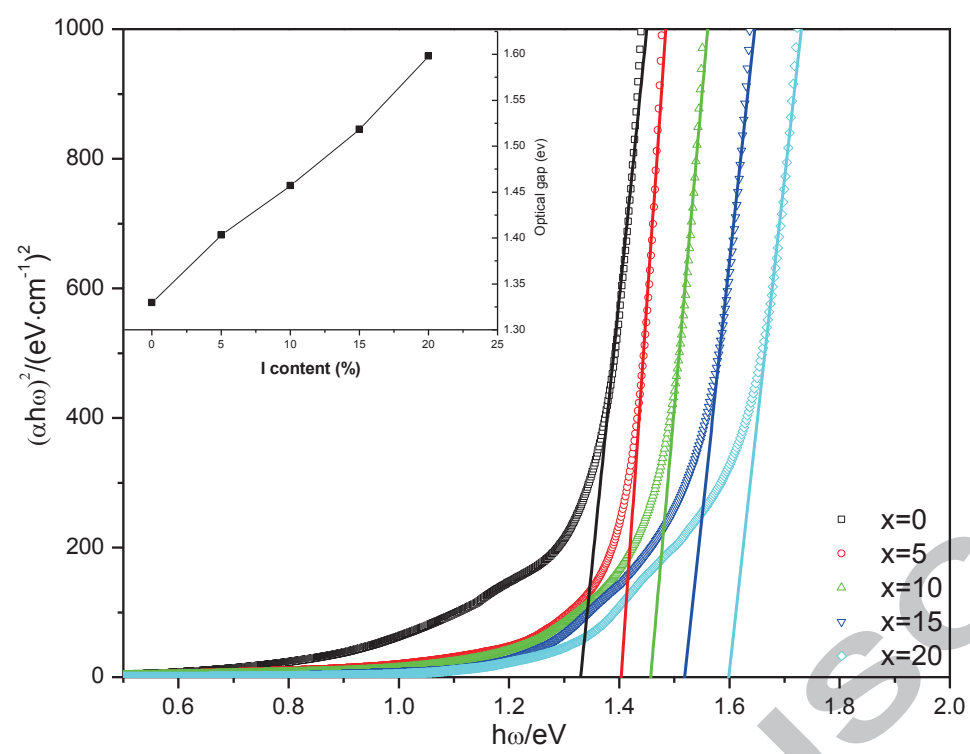

Fig. 7. Relationship between $(\alpha(\omega) \hbar \omega)^{2}$ and $\hbar \omega$ for glass samples. The upper left inset figure shows the relationship between the optical gap $E_{o p t}$ and I contents.

\subsection{Raman Peak Fitting and Analysis}

We adopted the Raman spectra of the glasses to reveal the structure evolutions in this glass system, further understand the experiment results, and confirm the analysis in the above section. The fitted spectra presented in this section were background corrected and normalized to the maximum intensity of the broad band to determine the variation in structural units and influence of vibrational modes of each unit on the overall Raman spectrum. The compositional dependence of the Raman spectra of the $\mathrm{Ge}_{20} \mathrm{Sb}_{5} \mathrm{Se}_{75-\mathrm{x}} \mathrm{I}_{\mathrm{x}}$ glasses is presented in Fig. 8 and are dominated by several overlapping bands between 100 and $400 \mathrm{~cm}^{-1}$.

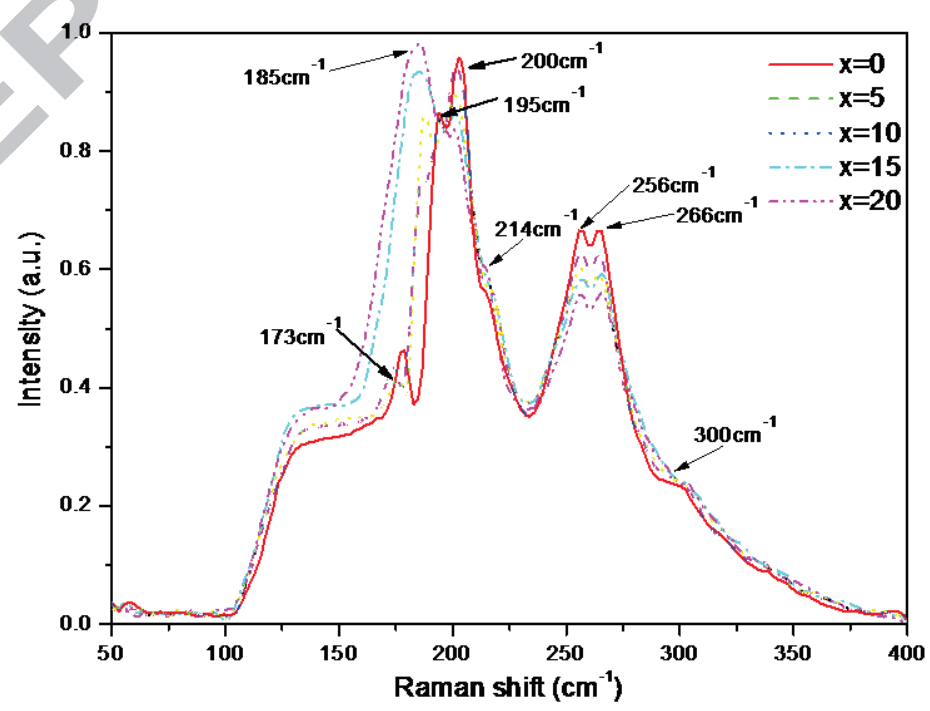

Fig. 8. Normalized Raman spectra of the $\mathrm{Ge}_{20} \mathrm{Sb}_{5} \mathrm{Se}_{75-\mathrm{x}} \mathrm{I}_{\mathrm{x}}$ glasses.

The general features that dominate the Raman spectrum of the glass can be summarized as follows:

(1) The most intense Raman band at $200 \mathrm{~cm}^{-1}$ and its shoulder called "companion peak" at 214 $\mathrm{cm}^{-1}$ are attributed to the symmetrical stretching vibration of $\mathrm{Ge}-\mathrm{Se}$ bonds in the corner-sharing 
$\mathrm{GeSe}_{4 / 2}$ tetrahedra and edge-sharing $\mathrm{Ge}_{2} \mathrm{Se}_{8 / 2}$ bi-tetrahedra, respectively [23, 24].

(2) The broad, low-intensity Raman band at $256 \mathrm{~cm}^{-1}$ and $266 \mathrm{~cm}^{-1}$ with a shoulder at $300 \mathrm{~cm}^{-1}$ is due to the vibration of $\mathrm{Se}_{\mathrm{n}}$ rings and $\mathrm{Se}-\mathrm{Se}$ chains, respectively [23, 24].

(3) The shoulder at $173 \mathrm{~cm}^{-1}$ is associated with the vibrations of related $\mathrm{Ge}-\mathrm{Ge}$ bonds in the $\mathrm{Se}_{3} \mathrm{Ge}-\mathrm{GeSe}_{3}$ units [25].

(4) The peak at $195 \mathrm{~cm}^{-1}$ can be ascribed to the vibration of the heteropolar $\mathrm{Sb}-\mathrm{Se}$ bonds in $\mathrm{SbSe}_{3}$ pyramids connected through a bridging Se [26]. However, the peak is unclear in the Raman spectra because of its overlapping with the $\mathrm{Ge}-\mathrm{Se}$ vibrational bands and a low $\mathrm{Sb}$ concentration in the investigated glasses.

(5) The absence of the band at $150 \mathrm{~cm}^{-1}$ indicates the absence of $\mathrm{Sb}-\mathrm{Sb}$ bonds in the $\mathrm{Se}_{2} \mathrm{Sb}_{-}-\mathrm{SbSe}_{2}$ structural units [27], which is consistent with the very low $\mathrm{Sb}$ concentration in the investigated glasses.

The changes in Raman spectra with I incorporation has shown that:

(1) The amplitudes of the $200 \mathrm{~cm}^{-1}$ and $174 \mathrm{~cm}^{-1}$ bands are reduced, which shows the decrease in corner-shared $\left(\mathrm{GeSe}_{4}\right)$ tetrahedral and $\mathrm{Se}_{3} \mathrm{Ge}-\mathrm{GeSe}_{3}$ units in I incorporated glasses. The band at 174 $\mathrm{cm}^{-1}$ clearly disappears in the glasses with an I concentration of more than $10 \%$. Given that the bond energy of Ge-I is larger than that of Ge-Ge, Ge is preferentially bonded with I and would lead to the formation of $\mathrm{Ge}-\mathrm{I}$ bonds with the addition of I. Part of the Se atoms in the $\mathrm{GeSe}_{4}$ units are replaced by I atoms in the newly formed glass system. I can also break the $\left(\mathrm{Se}_{3} \mathrm{Ge}-\mathrm{GeSe}_{3}\right)$ units to form complex $\mathrm{GeSe}_{4-\mathrm{x}} \mathrm{I}_{\mathrm{x}}$ units, especially under the condition of a large amount of $\mathrm{I}$. Thus, the intensity of these bands decreases gradually. With the concentration of I increasing to $15 \%$, a significant new band emerges at $185 \mathrm{~cm}^{-1}$ and enlarges quickly because of the Ge-I vibration.

(2) The bands located at $214 \mathrm{~cm}^{-1}$ do not significantly vary until $x$ increases up to 20 . This scenario indicates that the incorporation of $\mathrm{I}$ in the glass network mainly breaks the connection of the corner-sharing $\mathrm{GeSe}_{4 / 2}$ tetrahedra units rather than the two edge-sharing $\mathrm{Ge}_{2} \mathrm{Se}_{8 / 2}$ bi-tetrahedra because of the more firm bonding of edge-sharing than corner-sharing.

(3) The other remarkable feature extracted from the peak fitting curve is the evolution of the ratio of the total defective Se-Se bonds to that of the whole Raman spectra as shown in Figure 8. The amplitude corresponding to the homopolar Se-Se bonds in the Se chains and rings remarkably decreases with the progressive introduction of I, which demonstrates the decrease in relative ratio of the homopolar Se-Se bonds.

All of these results can be connected with the variation in the attenuation loss and optical bandgap shown in Figs. 5 to 7. The existence of defective units in amorphous materials forms band-tails below the conduction band or above the valence band; the presence of more defects broadens the energy level of the band-tails and narrows the optical bandgap [28, 29]. The forming of the new $\mathrm{GeSe}_{4-\mathrm{x}} \mathrm{I}_{\mathrm{x}}$ units indicates that the dangling bonds in the Se chains, Se rings, and $\mathrm{GeSe}_{3}$ units have gradually been repaired. Thus, the absorption coefficient in the WAT of this I modified glass system decreases effectively.

\subsection{Analysis of the IR optical transmission and absorption}

The transparency of the $\mathrm{Ge}-\mathrm{Sb}-\mathrm{Se}-\mathrm{I}$ glass system extends from the band gap region at $0.94 \mu \mathrm{m}$ to the phonon region at approximately $17 \mu \mathrm{m}$ as shown in Fig. 9. A red-shift in the long wavelength cut-off edge is observed in the IR transmission with the increasing I content. The optical windows of these glasses are decided by the multi-phonon cut-off edges of very low energy that can be due to the intrinsic harmonic vibrational modes associated with Ge-Se and Ge-I covalent bonds in the vitreous matrix. The bond energy of Ge-Se (205.607 kJ mol-1) is the largest, so the long-wavelength cut-off 
edge located near $17 \mu \mathrm{m}$ is mainly decided by the Ge-Se vibration.

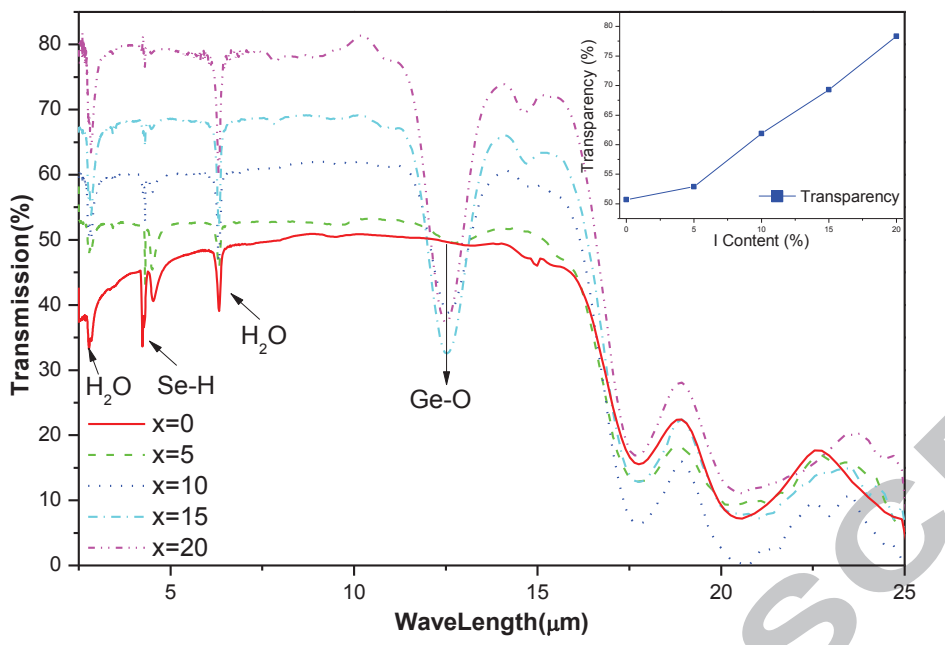

Fig. 9. IR transmission spectra of the glass sample. The upper right inset figure shows the mid-IR transparency at $10 \mu \mathrm{m}$ varying with I content.

The addition of I also has positive effects on improving the transparency of this glass system. The transmittance of IR light increased remarkably with the increasing I content. The maximum average transmission percentage in the mid-IR region can reach up to almost $80 \%$ with 20 at $\%$ of the I content. The increased transparency can be explained by the following two factors. On the one hand, the relatively smaller polarization of halogen I decreases the glass refractive index with the increasing I content, which brings less Fresnel's reflective losses. On the other hand, unlike the original Ge-Sb-Se glass system, the less glass net-work defects and gradually enhanced glass-forming ability lead to a decreased scattering loss in the ameliorative glass system.

Given that the transmittance of glass material is essentially determined by its absorption degree of light, we calculated that the total absorption coefficient of every glass sample and attempted to quantitatively understand the change in glass transparency. For a bulk glass sample with thickness $l$ and reflectivity $R$ immersed in air for measurement, we assumed its refractive index as $n$ and compared it with the air value of 1 . Thus, the Fresnel's equation can be simplified as follows:

$$
R=(n-1)^{2} /(n+1)^{2}
$$

With the help of Beer's law, the transmittance $T$ can then be described by the following equation:

$$
T=\left(1-R_{1}\right) e^{-\alpha l}\left(1-R_{2}\right)
$$

where $\alpha, l$, and $R$ represent the absorption coefficient, sample thickness, and reflectivity, respectively. The internal and external surfaces of a bulk glass are nearly the same, so $\mathrm{R}_{1}=\mathrm{R}_{2}$. We can then set $A=$ $e^{-\alpha l}$, so Equation (10) can be expressed as follows:

$$
T=(1-R)^{2} e^{-\alpha l}=(1-R)^{2} A
$$

Because $\alpha \geq 0,0<\mathrm{A} \leq 1$. When $\alpha=0, A=1$, the glass has no absorption of light except the inner reflection, which makes it an ideally transparent material. When $\alpha \rightarrow \infty, A \rightarrow 0$, the glass is opaque. Fig. 10 shows the transmission of a light beam passing through a bulk glass. 


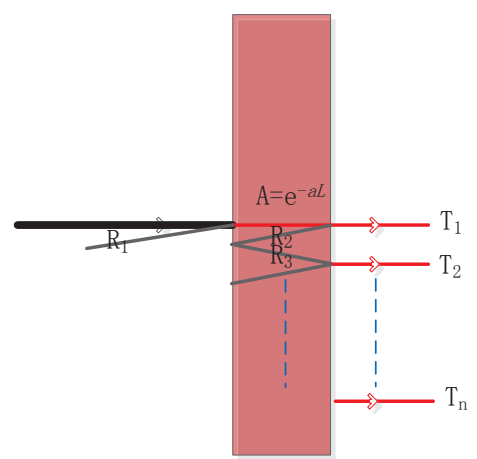

Fig. 10. Diagram of the transmission path when light passes through a bulk glass.

Each component of light permeated through the glass can then be expressed as follows:

$$
\left\{\begin{array}{l}
T_{1}=(1-R)^{2} * A \\
T_{2}=(1-R)^{2} * A^{*} R^{2} * A^{2} \\
\cdots \\
T_{n}=(1-R)^{2} * A^{*} R^{2 n} * A^{2 n}
\end{array}\right.
$$

We can obtain the total transmission $T$ (Eq. 13) by making a summation from $T_{1}$ to $T_{\mathrm{n}}$ as follows:

$$
\begin{aligned}
T=T_{\text {total }} & =T_{1}+T_{2}+\cdots T_{n}+\cdots=\sum_{n=1}^{\infty} T_{n} \\
& =\lim _{n \rightarrow \infty}(1-R)^{2} * A^{*}\left(1+R^{2} A^{2}+\cdots+R^{2 n} A^{2 n}\right) \\
& =\lim _{n \rightarrow \infty}(1-R)^{2} * A^{*}\left(1-R^{2 n} A^{2 n}\right) /\left(1-R^{2} A^{2}\right) \\
& =\frac{(1-R)^{2} * A}{1-R^{2} A^{2}}
\end{aligned}
$$

$T$ has been determined beforehand in the above equation, so we can work out $A$. Thus:

$$
A=-\frac{1-2 R+R^{2}-\sqrt{1-4 R+6 R^{2}-4 R^{3}+R^{4}+4 T^{2} R^{2}}}{2 T R^{2}}
$$

We can then obtain the total absorption coefficient $\alpha$ in the whole wavelengths $(2.5 \mu \mathrm{m}-18 \mu \mathrm{m})$ as shown in Fig. 11.

The absorption bands shown in Figs. 9 and 11 can be ascribed to the presence of extrinsic impurities. The most intensive absorption peak in the IR region is located at $12.5 \mu \mathrm{m}$, which is ascribed to the vibration of the $\mathrm{Ge}-\mathrm{O}$ covalent bond [30]. The impurity absorption peak of the $\mathrm{Ge}-\mathrm{O}$ bonds are clearly strengthened when the I content increases. This condition is caused by the halogen I being generally more unstable against hydrolization than the elements $\mathrm{Ge}, \mathrm{Sb}$, and $\mathrm{Se}$. In particular, the oxide and water impurities introduced through the raw materials are increased. Given that no special purification has been performed, the absorption bands located at $4.3 \mu \mathrm{m}$ can be ascribed to the $\mathrm{Se}-\mathrm{H}$ covalent bond vibration. The absorption band at $6.3 \mu \mathrm{m}$ and $2.8 \mu \mathrm{m}$ can be caused by $\mathrm{H}_{2} \mathrm{O}$ impurities [30]. 
The general changing trend in Fig. 11(a) is that the absorption decreases significantly with the increasing I content. Unlike the original Ge-Sb-Se glass sample, the slope near $2.5 \mu \mathrm{m}$ has become a flat curve in the new Ge-Sb-Se-I system because of the decrease in the WAT in the short wavelength. The value of $\alpha$ has gradually decreased from $2.741 \mathrm{~cm}^{-1}$ to $0.103 \mathrm{~cm}^{-1}$ as shown in Fig. 11(b). We have obtained the lowest absorption coefficient of $0.029 \mathrm{~cm}^{-1}$ at the wavelength of $10.16 \mu \mathrm{m}$ for the $\mathrm{I}_{20}$ glass in the region of $8 \mu \mathrm{m}$ to $13 \mu \mathrm{m}$ atmospheric window.

All these results suggest that the halogen I can effectively decrease the absorption and improve the optical properties of the original Ge-Sb-Se glass. These conditions have been fully embodied in the changes in the images taken by the near IR camera (Fig. 1).

However, even the introduction of I can bring many advantages to the new glass system. Some impurities are also introduced with I. We cannot preheat the ampoule containing the raw materials during the process of vacuum-pumping to prevent the sublimation of I, Given to the strong hydrophilicity of I, more extrinsic impurities related to $\mathrm{H}_{2} \mathrm{O}$ are introduced.

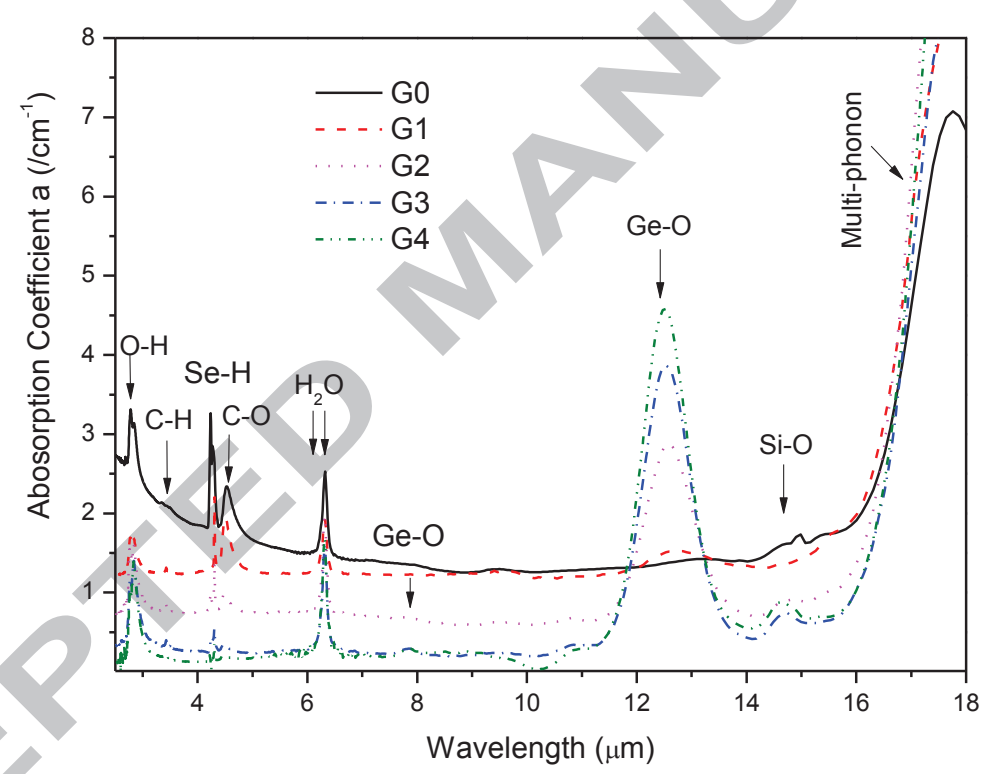




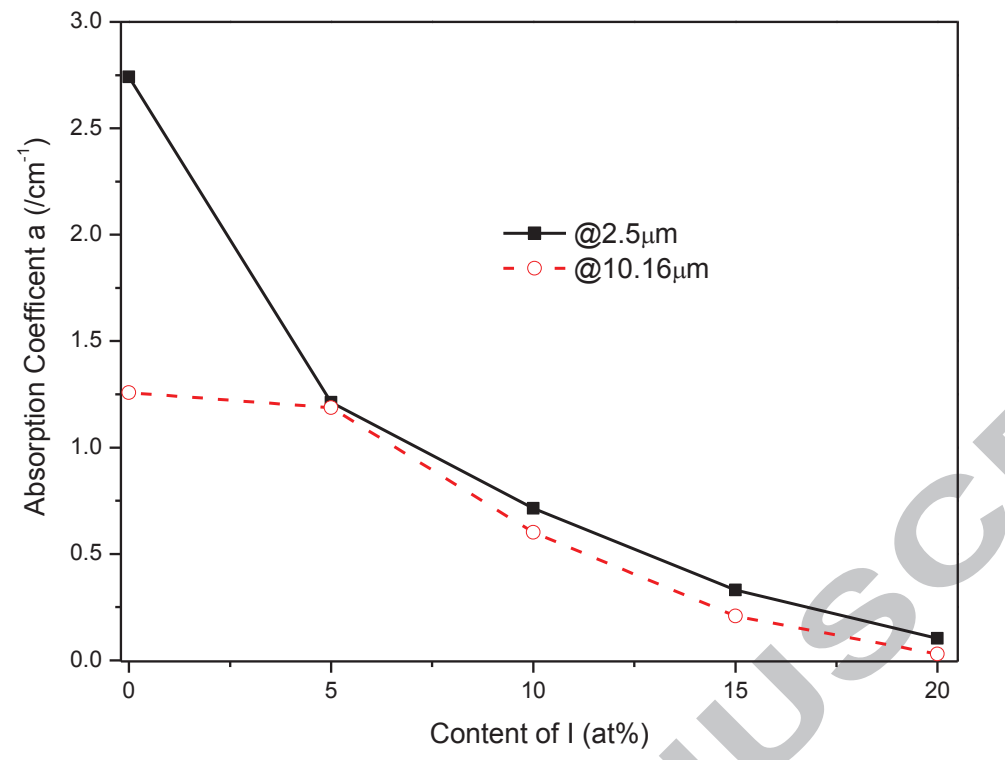

Fig. 11. (a) Total absorption coefficient $\alpha$ of glass samples. (b) Variation of $\alpha$ with the I content at the wavelengths of $2.5 \mu \mathrm{m}$ and $10.16 \mu \mathrm{m}$.

\section{Conclusions}

A series of $\mathrm{Ge}-\mathrm{Sb}-\mathrm{Se}-\mathrm{I}$ chalcohalide glasses were prepared and some key properties were investigated systematically. The chemical bond, optical bandgap, light absorption and transmission mechanism, as well as the evolution of the glass structure were all discussed. The halogen I can effectively decrease the glass defects by decreasing the amount of dangling bonds in the glass network, which improves the optical properties of the original Ge-Sb-Se glass system. With the progressive substitution of I for Se from $\mathrm{x}=5$ to $\mathrm{x}=20$, the optical bandgap clearly increases and the WAT decreases significantly. The absorption coefficient $\alpha$ decreases from $2.741 \mathrm{~cm}^{-1}$ to $0.103 \mathrm{~cm}^{-1}$ in the short wavelength region of 2.5 $\mu \mathrm{m}$. We obtained the lowest $\alpha$ of $0.029 \mathrm{~cm}^{-1}$ for the $\mathrm{I}_{20}$ glass at the $10.16 \mu \mathrm{m}$ wavelength. The achieved maximum IR transparency of the new Ge-Sb-Se-I glass system was near $80 \%$ with an effective transmission window between $0.94 \mu \mathrm{m}$ to $17 \mu \mathrm{m}$. If the Ge-Sb-Se-I glass can be further purified, its transmitting window would be flatter.

\section{Acknowledgments}

This work was financially supported by the National Program on Key Basic Research Project (973 Program) (Grant No. 2012CB722703), The Natural Science Foundation of China (Grant Nos. 61377099, 61435009 and 61177087), Scientific Research Fund of Zhejiang Provincial Education Department (R1101263), Natural Science Foundation of Ningbo (Grant No. 2013A610118), Teaching and Research Award Program for Outstanding Young Teachers in Higher Education Institutions of MOE, P.R.C. Ningbo Optoelectronic Materials and Devices Creative Team (2009B21007), Scientific Research Foundation of the Graduate School of Ningbo University, and the K. C. Wong Magna Fund of Ningbo University.

\section{References}



(2008) 432-442. 26632-26634

S. Maurugeon, C. Boussard-Plédel, J. Troles, A. J. Faber, P. Lucas, X. Zhang, J. Lucas, B. Bureau, Telluride Glass Step Index Fiber for the far Infrared, J. Lightwave Technol. 28(23) (2010) 3358-3363.

D. L. Wood, J. Tauc, Weak Absorption Tails in Amorphous Semiconductors, Phys. Rev. B. 5(8) (1972) 3144-3151

J. S. Sanghera, I. D. Aggarwal, Development of chalcogenide glass fiber optics at NRL, J. Non-Cryst. Solids 213 (1997) 63-67.

W. Jin Chung, B. Je Park, H. Seok Seo, J. Tae Ahn, M.-H. Lee, Y. G. Choi, Effects of the Weak Absorption Tail on the Transmission Loss of Ge-Sb-Se Optical Fibers, J. Am. Ceram. Soc. 88(5) (2005) 1205-1208

S. Danto, P. Houizot, C. Boussard-Pledel, X. Zhang, F. Smektala, J. Lucas, A family of far-infrared-transmitting glasses in the Ga-Ge-Te system for space applications, Adv. Funct. Mater. 16(14) (2006) 1847-1852.

H. Wang, G. Yang, Y. Xu, X. Zhang, Z. Gu, G. Chen, Formation of new chalcohalide glasses in $\mathrm{GeSe}_{2}-\mathrm{Ga}_{2} \mathrm{Se}_{3}-\mathrm{KI}$ system, J. Chin. Ceram. Soc. 35(7) (2007) 922-925

S. M. El-sayed, H. M. Saad, G. A. Amin, F. M. Hafez, M. Abd-El-Rahman, Physical evolution in network glasses of the Ag-As-Te system, J. Phys. Chem. Solids 68(5-6) (2007) 1040-1045.

L. Pauling, The Nature of Chemical Bonds, Cornell University Press, 1960.

A. S. Soltan, M. Abu El-Oyoun, A. A. Abu-Sehly, A. Y. Abdel-Latief, Thermal annealing dependence of the structural, optical and electrical properties of selenium-tellerium films, Mater. Chem. Phys. 82(1) (2003) 101-106.

V. Sadagopan, H. C. Gatos, On the relationship of semiconductor compound properties and the average heats of atomisation, Solid-State Electron. 8(6) (1965) 529-534.

J. A. Duffy, Chemical bonding in the oxides of the elements: A new appraisal, J. Solid State Chem. 62(2) (1986) $145-157$.

V. Dimitrov, T. Komatsu, Effect of interionic interaction on the electronic polarizability, optical basicity and binding energy of simple oxides, J. Ceram. Soc. Jpn. 107(11) (1999), 1012-1018.

V. Dimitrov, S. Sakka, Linear and nonlinear optical properties of simple oxides. II, J. Appl. Phys. 79(3) (1996), 1741-1745. J. Tauc, Amorphous and Liquid Semiconductors, Plenum Press, 1974.

T. Kanamori, Y. Terunuma, S. Takahashi, T. Miyashita, Chalcogenide glass fibers for mid-infrared transmission, J. Lightwave Technol 2(5) (1984) 607-613.

D. Brady, T. Schweizer, J. Wang, D. Hewak, Minimum loss predictions and measurements in gallium lanthanum sulphide based glasses and fibre, J. Non-Cryst. Solids 242(2) (1998) 92-98.

21 W. Jin Chung, B. Je Park, H. Seok Seo, J. Tae Ahn, M. H. Lee, Y. G. Choi, Effects of the weak absorption tail on the transmission loss of Ge-Sb-Se optical fibers, J. Am. Ceram. Soc. 88(5) (2005) 1205-1208.

C. Liu, G. Tang, L. Luo, W. Chen, Effect of CsI addition on the thermal properties, crystallization kinetics and short-wavelength absorption edges of $\mathrm{GeSe}_{2}-\mathrm{Ga}_{2} \mathrm{Se}_{3}$ glasses, J. Alloy. Compd. 474(1-2) (2009), 468-472.

S. El-Sayed, Far-infrared studies of the amorphous $\mathrm{Sb}_{\mathrm{x}} \mathrm{Ge}_{28-\mathrm{x}} \mathrm{Se}_{72}$ glassy semiconductor, Semicond. Sci. Technol. 18(4) (2003) 337 182-185. 
J. Holubova, Z. Černošek, E. Černošková, $\mathrm{Sb}_{\mathrm{x}} \mathrm{Se}_{100-\mathrm{x}}$ system $(0 \leq \mathrm{x} \leq 8)$ studied by DSC and Raman spectroscopy, Optoelectron. Adv. Mat. 1(12) (2007) 663-666.

27 Z. Ivanova, E. Cernoskova, V. Vassilev, S. Boycheva, Thermomechanical and structural characterization of $\mathrm{GeSe}_{2}-\mathrm{Sb}_{2} \mathrm{Se}_{3}-\mathrm{ZnSe}$ glasses, Mater. Lett. 57(5) (2003) 1025-1028.

K. Hachiya, Electronic structure of the wrong-bond states in amorphous germanium sulphides, J. Non-Cryst. Solids 321(3) (2003) 217-224.

D. Vanderbilt, J. Joannopoulos, Theory of defect states in glassy $\mathrm{As}_{2} \mathrm{Se}_{3}$, Phys. Rev. B 23(6) (1981) 2596.

T. Katsuyama, K. Ishida, S. Satoh, H. Matsumura, Low loss Ge-Se chalcogenide glass optical fibers, Appl. Phys. Lett. 45(9) (1984) 925. 
Highlights:

1. A series of Ge-Sb-Se-I chalcohalide glasses were prepared and some key properties were investigated systematically.

2. The mechanisms of the halogen I affecting the physical, thermal, and optical properties of Se-based chalcogenide glasses were reported.

3. The mid-IR transparency of conventional Ge-Sb-Se chalcogenide glasses was improved with iodine incorporation.

4. The structural evolutions of Ge-Sb-Se-I glasses were revealed by Raman spectroscopy and the intensity of weak absorption tail was decreased by decreasing glass network defects. 